\title{
Aspectos macro e micropoliticos na organização do trabalho no NASF: o que a produção científica revela?
}

I ${ }^{1}$ Daiene Aparecida Alves Mazza, ${ }^{2}$ Brígida Gimenez Carvalho,
${ }^{3}$ Marselle Nobre de Carvalho, ${ }^{4}$ Fernanda de Freitas Mendonça I

Resumo: Este artigo objetiva analisar a influência dos aspectos macro e micropolíticos na organização e processo de trabalho do NASF. Trata-se de uma scoping review, realizada durante o mês de junho de 2020, nas bases de dados Lilacs e Medline. Identificou-se que questóes referentes à infraestrutura, gestão do trabalho do NASF, formação para o SUS, relação entre as equipes e características dos profissionais do NASF influenciam a organização e o processo de trabalho do NASF, evidenciando-se a ocorrência de um maior número de desafios, em detrimento das potencialidades para esse processo. Destaca-se que atravessamentos marcados pela conjuntura atual podem refletir incisivamente no trabalho dessas equipes. Aponta-se a necessidade da implantação de estratégias no sentido de dirimir os obstáculos desvelados por este estudo, tais como a criação de espaços de educação permanente no cotidiano das equipes, o estabelecimento de ferramentas de cogestáo, e o incentivo a iniciativas que fomentem a integração ensino-serviço-comunidade.

> Palavras-chave: Atenção Primária à Saúde; equipe multiprofissional; prática de saúde pública; política de saúde.

\author{
${ }^{1}$ Universidade Estadual de \\ Londrina. Londrina-PR, Brasil \\ (daifisiouel@yahoo.com.br). \\ ORCID: 0000-0002-0011-8944 \\ ${ }^{2}$ Universidade Estadual de \\ Londrina. Londrina-PR, Brasil \\ (brigidagimenez@gmail.com). \\ ORCID: 0000-0003-3850-870X \\ ${ }^{3}$ Universidade Estadual de \\ Londrina. Londrina-PR, Brasil \\ (marsellecarvalho@gmail.com) \\ ORCID: 0000-0001-7338-5448 \\ ${ }^{4}$ Universidade Estadual de \\ Londrina. Londrina-PR, Brasil \\ (fernanda0683@gmail.com). \\ ORCID: 0000-0002-3532-5070
}

Recebido em: 18/02/2020 Aprovado em: 28/06/2020 Revisado em: 03/10/2020 


\section{Introdução}

O Núcleo de Apoio à Saúde da Família (NASF) foi criado pelo Ministério da Saúde (MS) em 2008 (BRASIL, 2008), com o objetivo de apoiar as equipes de referência para ampliar a abrangência e a resolutividade de suas açôes (CAMPOS et al., 2014), contribuindo para a oferta de cuidado integral na saúde (ARAÚJO NETO et al., 2019) e para a consolidação da Atenção Básica (AB) no Brasil. O NASF é constituído por profissionais de diferentes núcleos de conhecimento e práticas, cujo suporte especializado pode ser realizado por meio de discussôes clínicas, intervençóes conjuntas com a equipe de referência e assistência direta aos casos que demandam açóes especializadas (CAMPOS et al., 2014).

Preconiza-se que o processo de organização do trabalho do NASF seja pautado segundo a lógica do apoio matricial, por relação colaborativa com os profissionais da equipe de referência, a fim de priorizaro atendimento compartilhado einterdisciplinar, contemplando as dimensóes técnico-pedagógica e clínico-assistencial (BRASIL, 2008, 2014). Quando operado na dimensão técnico-pedagógica, o apoio matricial se destina ao respaldo educativo para a equipe de referência. Por sua vez, a dimensão clínico-assistencial permite discernir casos e situaçôes que podem ser acompanhadas pela equipe de referência daquelas que necessitam ser compartilhadas com o NASF ou com a rede (CAMPOS et al., 2014).

Ao longo do processo de implementação do NASF, o MS publicou vários materiais no intuito de qualificar o trabalho do Núcleo (BRASIL 2009a, 2014, 2017). No entanto, apesar dessas iniciativas, é notável a dificuldade das equipes do NASF em atuar conforme preconizam as portarias e diretrizes vigentes (ANJOS et al., 2013; GONÇALVES et al., 2015). Ademais, a atual conjuntura aponta medidas governamentais que operam na contramão do Sistema Único de Saúde (SUS) e de um trabalho pautado no apoio matricial e na interprofissionalidade, como o reconhecimento de outras formas de organização da $A B$ para além da saúde da família (BRASIL, 2017; FERREIRA; LADEIA, 2018; MELO et al., 2018a; MOROSINI; FONSECA; LIMA, 2018). Há também a ausência de financiamento específico para as equipes do NASF e a desvinculação da composiçâo dessas equipes ao modelo "NASF", inclusive com alteração da nomenclatura para Núcleos Ampliados de Saúde da Família e Atenção Básica (NASF-AB) (BRASIL, 2019a).

Aspectos micro e macropolíticos interferem na organização do trabalho desses núcleos nas diversas localidades em que estão implantados. Para este artigo, 
tomou-se como referência a definição de micropolítica expressa por Luiz Cecílio, como sendo um "[...] conjunto de relaçôes que estabelecem, entre si, os vários atores organizacionais, formando uma rede complexa, móvel, mutante, mas com estabilidade suficiente para constituir uma determinada 'realidade organizacional'" (CECÍlIO, 2007, p. 10). Para o autor, no ambiente de trabalho, as pessoas são portadoras de valores, de projetos, de interesses e disputam sentidos para o trabalho em saúde. Dessa forma, o espaço de trabalho é sempre um campo marcado por disputas, acordos, composiçôes, coalizôes e afetos; um campo constituído e atravessado por relaçôes de poder. Tomando por base o conceito de micropolítica, numa escala que extrapola as relaçóes entre os trabalhadores, adotou-se o conceito de macropolítica enquanto processos que se articulam ao contexto organizacional e o conformam, ou seja, os aspectos estruturais da organização da sociedade, como a legislação e as normas além da conformação e estrutura dos serviços de saúde.

O trabalho em saúde na perspectiva da colaboração interprofissional tem sido alvo de diversas pesquisas pelo mundo (BARR et al., 2005). Estudos evidenciam que a colaboração interprofissional leva a melhorias organizacionais e a benefícios ao atendimento do paciente em diferentes serviços de saúde (GILLES et. al., 2020), particularmente aqueles com necessidades complexas (MULVALE; EMBRETT; RAZAVI, 2016), o que é essencial para cumprir a oferta de atenção à saúde integral (BARR et al., 2005). Além disso, um estudo de revisão sistemática aponta evidências de que a equipe, cujos profissionais possuem visão e objetivos compartilhados, se sentem parte da equipe (aspectos micropolíticos), favorecendo as práticas colaborativas. No entanto, é apontado também que poucos estudos avaliaram associações entre colaboração e fatores macro, recomendando dar prioridade para pesquisas futuras (MULVALE; EMBRETT; RAZAVI, 2016).

De acordo com Reeves (2016), somente a partir de maiores produçóes de evidências cientificas é que se poderá avançar efetivamente no planejamento e na implementação de práticas colaborativas que possam beneficiar à atenção ao paciente. Nesse sentido, questiona-se: como acontece o processo de trabalho do NASF? Que elementos orientam os diferentes arranjos assumidos no processo de trabalho das equipes NASF? Buscando responder a essas questôes, foi desenvolvida uma scoping review que teve por objetivo analisar os aspectos micro e macropolíticos que influenciam ou orientam a organização e o processo de trabalho no NASF. 


\section{Procedimento metodológico}

Optou-se por realizar uma scoping review ou scoping study, abordagem cada vez mais utilizada para analisar evidências de pesquisa em saúde. Consiste em um tipo de revisão de literatura proposta pelas pesquisadoras Hilary Arksey e Lisa O'Malley em 2005, que permite examinar a extensão, o alcance e a natureza da atividade de pesquisa, resumir e divulgar resultados de estudos e, também, identificar as lacunas de pesquisa na literatura existente (LEVAC; COLQUHOUN; O’BRIEN, 2010). O estudo seguiu as seguintes etapas: (1) identificação da questão da pesquisa; (2) identificação dos estudos relevantes; (3) seleçấo dos estudos; (4) mapeamento dos dados; e (5) confrontação, resumo e relato dos resultados.

Esta revisão teve como questão norteadora a necessidade de compreender os fatores que influenciam ou orientam a organização e o processo de trabalho do NASF, em âmbito nacional, considerando as diversas realidades nas quais essas equipes estão inseridas. Para o estudo, foram utilizados como critérios de inclusão artigos originais que apresentavam resumos de livre acesso; nos idiomas português, inglês e/ou espanhol; publicados no período de 2008 a 2020, tendo em vista que a criação do NASF ocorreu com a publicação da Portaria no 154 em 2008. Foram excluídos da pesquisa livros ou capítulos, monografias, teses, dissertaçôes, documentos oficiais e estudos tipo revisão.

A busca bibliográfica foi realizada durante o mês de junho de 2020, nas bases de dados: Literatura Latino-Americana e do Caribe em Ciências da Saúde (Lilacs) e Medical Literature Analysis and Retrieval System Online (Medline). Foram utilizados os seguintes Descritores em Ciências da Saúde (DeCS): Atenção Primária à Saúde; Prática de Saúde Pública; Estratégia Saúde da Família; Administração de Serviços de Saúde; Serviços de saúde; Primary Health Care; Public Health Practice; Family Health Strategy; Health Services Administration; e Health Services.

Para a busca nas bases de dados, os descritores foram dispostos acrescidos da palavra "NASF", com o operador booleano and, da seguinte forma: atenção primária à saúde and NASF; atenção primária à saúde and práticas de saúde pública and NASF; atenção primária à saúde and Estratégia Saúde da Família and NASF; atenção primária à saúde and Administração de Serviços de Saúde and NASF; atenção primária à saúde and Serviços de saúde and NASF; Primary Health Care and NASF; Primary Health Careand Public Health Practiceand NASF; Primary Health Care and Family Health Strategyand NASF; Primary Health Careand; Health Services Administration and NASF; Primary Health Care and Health Services and NASF. 
O percurso metodológico utilizado para a seleção dos artigos integrantes do estudo está expresso na figura 1. Dessa forma, dos 101 artigos selecionados inicialmente, a presente scoping review foi composta por 26 artigos, sendo três na base de dados Medline e 23 na Lilacs. Para a organização dos dados selecionados pelo estudo, foram identificados: ano de publicação, título, autoria, revista de publicação e objetivo do estudo (quadro 1). Após a leitura dos materiais, as informações referentes aos fatores que influenciam ou orientam a organização e o processo de trabalho do NASF foram mapeados e confrontados entre si, procedendo-se, então, ao resumo destas informaçôes e ao relato dos resultados.

Figura 1. Percurso metodológico para seleção dos artigos integrantes da scoping review. Londrina-PR, 2020

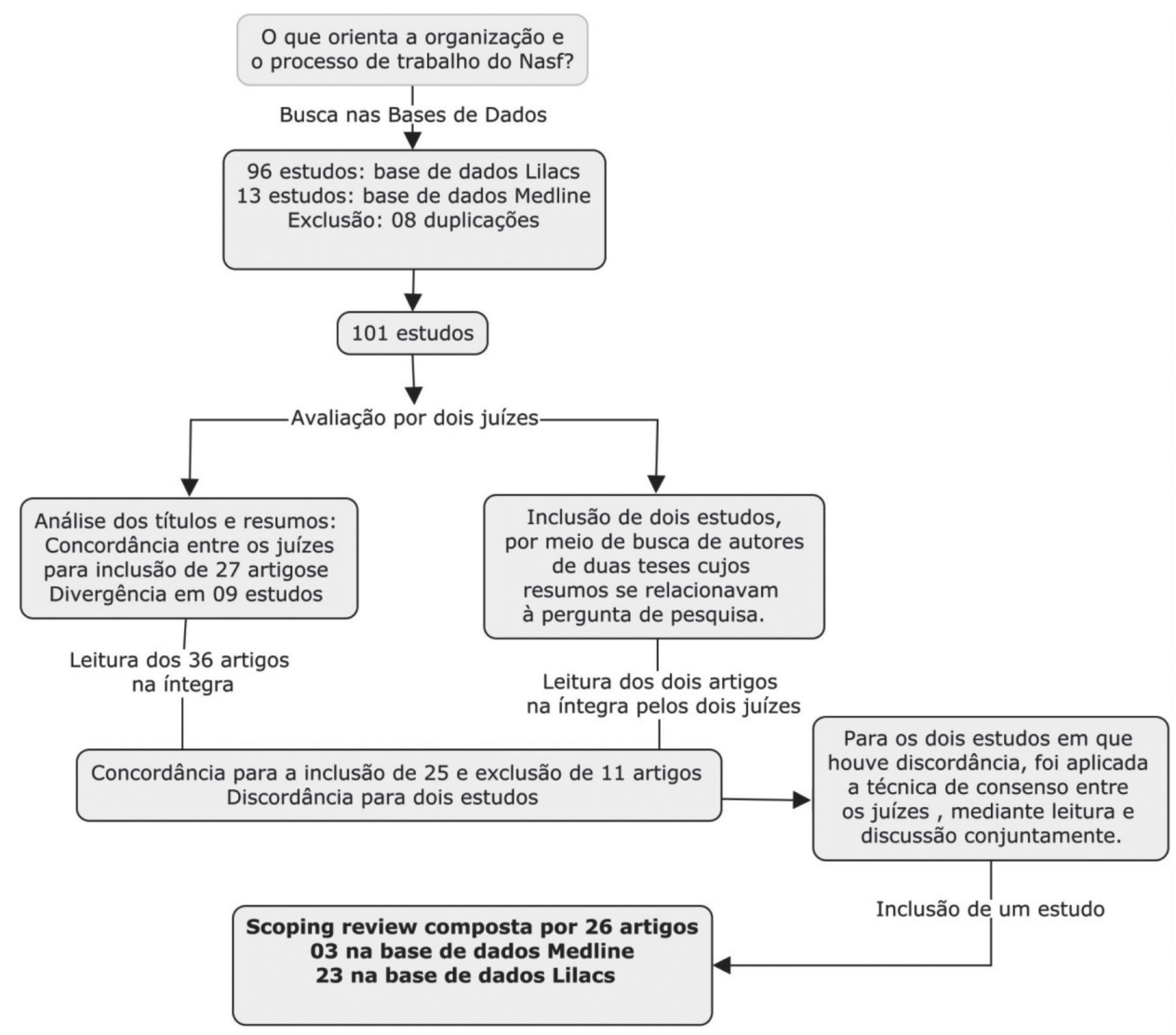

Fonte: os autores, 2020. 
Os resultados foram categorizados e analisados de acordo com a influência exercida pelos fatores micro e macropolíticos. Cabe destacar, no entanto, que a separação entre os fatores feita neste estudo é puramente didática, a fim de auxiliar a análise dos fatores que interferem na organização e no processo de trabalho do NASF. É nítido para os autores que as dimensōes micro e macropolítica não são estanques ou separadas; ao contrário, se relacionam, se imbricam e se complementam (MALTA; MERHY, 2010), ou seja, integram um mesmo contexto.

\section{Resultados}

Dos 26 artigos selecionados, dois analisaram o processo de trabalho do NASF a partir de dados provenientes do Programa de Melhoria do Acesso e da Qualidade na Atenção Básica - PMAQ; dez abordaram o desenvolvimento do processo de trabalho de categorias profissionais específicas no NASF; dois pesquisaram os processos de educação permanente vivenciados pelo NASF; sete relatam sobre o desenvolvimento do trabalho pelos profissionais do NASF, com ênfase nas ferramentas tecnológicas; um analisou a implantação do NASF com base nas diretrizes nacionais e a implementação local; um abordou a respeito do trabalho compartilhado e colaboração interprofissional; um identificou os fatores que afetam a qualidade de vida no trabalho de profissionais do NASF; um analisou analisar os aspectos restritivos ao princípio da integralidade envolvendo o processo de trabalho do NASF; e um verificou as características da organização e condiçôes de trabalho do NASF a partir da Análise Ergonômica do Trabalho e Ação em Psicodinâmica do Trabalho. Os estudos foram publicados a partir do ano de 2010, sendo 30\% (6) em 2013, ocasião em que havia 2.053 equipes de NASF implantadas no Brasil (BRASIL, 2019b). O quadro 1 traz a descrição dos artigos que integram este estudo. 
Quadro 1. Descrição dos estudos que integraram a scoping review. Londrina-PR, 2020

\begin{tabular}{|c|c|c|c|c|}
\hline $\begin{array}{c}\text { Ano de } \\
\text { Publicação }\end{array}$ & Título & Autores & Revista & Objetivos do estudo \\
\hline 2019 & $\begin{array}{l}\text { O apoio matricial na } \\
\text { Atenção Primária em } \\
\text { Saúde no município } \\
\text { do Rio de Janeiro: } \\
\text { uma percepção dos } \\
\text { matriciadores com foco } \\
\text { na Saúde Mental }\end{array}$ & $\begin{array}{l}\text { CHAZAN, Luiz } \\
\text { Fernando. }\end{array}$ & $\begin{array}{l}\text { Physis: Revista } \\
\text { de Saúde } \\
\text { Coletiva }\end{array}$ & $\begin{array}{l}\text { Analisar as percepçóes } \\
\text { do trabalho dos } \\
\text { matriciadores de saúde } \\
\text { mental do município do } \\
\text { Rio de Janeiro }\end{array}$ \\
\hline 2019 & $\begin{array}{l}\text { Atuação } \\
\text { fonoaudiológica no } \\
\text { NASF do município de } \\
\text { Santa Rita - PB }\end{array}$ & $\begin{array}{l}\text { SILVA, Nieliton } \\
\text { Costa et.al. }\end{array}$ & $\begin{array}{l}\text { Distúrbios da } \\
\text { Comunicação }\end{array}$ & $\begin{array}{l}\text { Caracterizar a atuação } \\
\text { fonoaudiológica no } \\
\text { NASF do município de } \\
\text { Santa Rita }\end{array}$ \\
\hline 2018 & $\begin{array}{l}\text { Aspectos restritivos } \\
\text { à integralidade nos } \\
\text { Núcleos de Apoio à } \\
\text { Saúde da Família: o } \\
\text { olhar dos stakeholders }\end{array}$ & $\begin{array}{l}\text { NETO, João Dutra } \\
\text { de Araujo et.al. }\end{array}$ & $\begin{array}{l}\text { Physis: Revista } \\
\text { de Saúde } \\
\text { Coletiva }\end{array}$ & $\begin{array}{l}\text { Analisar os aspectos } \\
\text { restritivos ao princípio } \\
\text { da integralidade, em } \\
\text { um município do } \\
\text { Nordeste do Brasil }\end{array}$ \\
\hline 2018 & $\begin{array}{l}\text { Núcleo de Apoio à } \\
\text { Saúde da Família } \\
\text { (NASF): panorama } \\
\text { nacional a partir de } \\
\text { dados do PMAQ }\end{array}$ & $\begin{array}{l}\text { BROCARDO, } \\
\text { Deniclara et al }\end{array}$ & $\begin{array}{l}\text { Saúde em } \\
\text { Debate }\end{array}$ & $\begin{array}{l}\text { Analisar o trabalho do } \\
\text { NASF, a partir de dados } \\
\text { do PMAQ }\end{array}$ \\
\hline 2018 & $\begin{array}{l}\text { Núcleos de apoio } \\
\text { à saúde da família: } \\
\text { concepçóes, } \\
\text { implicaçóes e desafios } \\
\text { para o apoio matricial }\end{array}$ & $\begin{array}{l}\text { BISPO JÚNIOR, } \\
\text { José Patrício; } \\
\text { MOREIRA, Diane } \\
\text { Costa }\end{array}$ & $\begin{array}{l}\text { Trabaho, } \\
\text { Educação e } \\
\text { Saúde }\end{array}$ & $\begin{array}{l}\text { Investigar os desafios } \\
\text { para a prática cotidiana } \\
\text { do apoio matricial, em } \\
\text { municípios da Bahia. }\end{array}$ \\
\hline 2018 & $\begin{array}{l}\text { Educação Permanente } \\
\text { em Saúde na atenção } \\
\text { ao idoso: dificuldades } \\
\text { e facilidades do Núcleo } \\
\text { de Apoio à Saúde da } \\
\text { Família }\end{array}$ & $\begin{array}{l}\text { NOGUEIRA, } \\
\text { Iara Sescon; } \\
\text { BALDISSERA, } \\
\text { Vanessa Denardi } \\
\text { Antoniassi. }\end{array}$ & $\begin{array}{l}\text { Escola Anna } \\
\text { Nery }\end{array}$ & $\begin{array}{l}\text { Pesquisar as } \\
\text { dificuldades e } \\
\text { facilidades da } \\
\text { Educação Permanente } \\
\text { desenvolvida pelo NASF } \\
\text { na atenção ao idoso }\end{array}$ \\
\hline
\end{tabular}




\begin{tabular}{|c|c|c|c|c|}
\hline $\begin{array}{c}\text { Ano de } \\
\text { Publicação }\end{array}$ & Título & Autores & Revista & Objetivos do estudo \\
\hline 2017 & $\begin{array}{l}\text { A atuação do psicólogo } \\
\text { nos NASF: desafios e } \\
\text { perspectivas na atenção } \\
\text { básica }\end{array}$ & $\begin{array}{l}\text { OLIVEIRA, Isabel } \\
\text { Fernandes de et al }\end{array}$ & $\begin{array}{l}\text { Temas em } \\
\text { Psicologia }\end{array}$ & $\begin{array}{l}\text { Analisar a atuação do } \\
\text { psicólogo no NASF, no } \\
\text { estado do RN, referente } \\
\text { aos modelos de atuaçáo } \\
\text { empregados e sua } \\
\text { consonância com os } \\
\text { princípios do SUS }\end{array}$ \\
\hline 2017 & $\begin{array}{l}\text { Educação permanente } \\
\text { e apoio matricial: } \\
\text { formação, vivências } \\
\text { e práticas dos } \\
\text { profissionais dos } \\
\text { Núcleos de Apoio à } \\
\text { Saúde da Família e das } \\
\text { equipes apoiadas }\end{array}$ & $\begin{array}{l}\text { BISPO JÚNIOR, } \\
\text { José Patrício; } \\
\text { MOREIRA, Diane } \\
\text { Costa }\end{array}$ & $\begin{array}{l}\text { Cadernos de } \\
\text { Saúde Pública }\end{array}$ & $\begin{array}{l}\text { Investigar como os } \\
\text { processos de educação } \\
\text { permanente são } \\
\text { vivenciados pelo NASF } \\
\text { e ESF. }\end{array}$ \\
\hline 2017 & $\begin{array}{l}\text { Processo de trabalho } \\
\text { entre a Equipe de } \\
\text { Atençáo Básica e o } \\
\text { Núcleo de Apoio à } \\
\text { Saúde da Família }\end{array}$ & $\begin{array}{l}\text { DA SILVA, Isabelle } \\
\text { Cristina Borba } \\
\text { et al. }\end{array}$ & $\begin{array}{l}\text { Revista } \\
\text { Brasileira de } \\
\text { Medicina } \\
\text { de Família e } \\
\text { Comunidade }\end{array}$ & $\begin{array}{l}\text { Estudar a organização } \\
\text { do processo de trabalho } \\
\text { entre o NASF e Equipes } \\
\text { AB, na Paraíba, através } \\
\text { de dados obtidos do } \\
\text { 2o Ciclo de Avaliação } \\
\text { Externa do PMAQ-AB }\end{array}$ \\
\hline 2016 & $\begin{array}{l}\text { A construção do } \\
\text { processo de trabalho } \\
\text { no Núcleo de Apoio } \\
\text { à Saúde da Família: } \\
\text { a experiência dos } \\
\text { farmacêuticos em um } \\
\text { município do sul do } \\
\text { Brasil }\end{array}$ & $\begin{array}{l}\text { NAKAMUR.A, } \\
\text { C.A.; LEITE, S. } \\
\text { N. }\end{array}$ & $\begin{array}{l}\text { Ciência } \\
\& \text { Saúde } \\
\text { Coletiva }\end{array}$ & $\begin{array}{l}\text { Investigar o } \\
\text { desenvolvimento do } \\
\text { processo de trabalho } \\
\text { dos farmacêuticos nos } \\
\text { NASF }\end{array}$ \\
\hline 2015 & $\begin{array}{l}\text { Matrix support } \\
\text { strategies: the } \\
\text { experience of two } \\
\text { Family Health Support } \\
\text { Centers (NASFs) in } \\
\text { São Paulo, Brazil. }\end{array}$ & $\begin{array}{l}\text { BARROS, Juliana } \\
\text { de Oliveira et al }\end{array}$ & $\begin{array}{l}\text { Ciência } \\
\& \text { Saúde } \\
\text { Coletiva }\end{array}$ & $\begin{array}{l}\text { Discutir como os } \\
\text { profissionais do NASF } \\
\text { desenvolvem seu } \\
\text { trabalho, com ênfase } \\
\text { na incorporaçáo do } \\
\text { matriciamento no } \\
\text { cotidiano das práticas. }\end{array}$ \\
\hline
\end{tabular}




\begin{tabular}{|c|c|c|c|c|}
\hline $\begin{array}{c}\text { Ano de } \\
\text { Publicação }\end{array}$ & Título & Autores & Revista & Objetivos do estudo \\
\hline 2015 & $\begin{array}{l}\text { Núcleo de Apoio à } \\
\text { Saúde da Família: } \\
\text { proposta nacional e } \\
\text { a implementaçáo em } \\
\text { municípios do estado } \\
\text { do Rio de Janeiro }\end{array}$ & $\begin{array}{l}\text { PATROCÍNIO, } \\
\text { Shirley Soares da } \\
\text { Silva Marins et al. }\end{array}$ & $\begin{array}{l}\text { Saúde em } \\
\text { Debate }\end{array}$ & $\begin{array}{l}\text { Analisar a implantação } \\
\text { do NASF como uma } \\
\text { estratégia da política de } \\
\text { AB brasileira, com base } \\
\text { nas diretrizes nacionais e } \\
\text { a implementação local. }\end{array}$ \\
\hline 2015 & $\begin{array}{l}\text { Colaboração } \\
\text { interprofissional na } \\
\text { Estratégia Saúde da } \\
\text { Família: implicações } \\
\text { para a produção do } \\
\text { cuidado e a gestão do } \\
\text { trabalho }\end{array}$ & $\begin{array}{l}\text { MATUDA, } \\
\text { Caroline Guinoza } \\
\text { et al }\end{array}$ & $\begin{array}{l}\text { Ciência } \\
\& \text { Saúde } \\
\text { Coletiva }\end{array}$ & $\begin{array}{l}\text { Captar a percepção } \\
\text { de profissionais que } \\
\text { atuam no NASF e na } \\
\text { ESF sobre o trabalho } \\
\text { compartilhado } \\
\text { e a colaboraçáo } \\
\text { interprofissional }\end{array}$ \\
\hline 2014 & $\begin{array}{l}\text { O Projeto Terapêutico } \\
\text { Singular e as práticas } \\
\text { de saúde mental nos } \\
\text { Núcleos de Apoio } \\
\text { à Saúde da Família } \\
\text { (NASF) em Guarulhos } \\
\text { (SP), Brasil. }\end{array}$ & $\begin{array}{l}\text { HORI, } \\
\text { Alice Ayako; } \\
\text { NASCIMENTO, } \\
\text { Andréia de Fátima }\end{array}$ & $\begin{array}{l}\text { Ciência } \\
\& \text { Saúde } \\
\text { Coletiva. }\end{array}$ & $\begin{array}{l}\text { Analisar a elaboração } \\
\text { de PTS pelas equipes } \\
\text { de SM dos NASF e } \\
\text { suas articulações com } \\
\text { serviços da APS, da } \\
\text { Atenção Psicossocial e } \\
\text { com outros setores }\end{array}$ \\
\hline 2014 & $\begin{array}{l}\text { O apoio institucional } \\
\text { como uma das faces da } \\
\text { funçáo apoio no Núcleo } \\
\text { de Apoio à Saúde da } \\
\text { Família (NASF): para } \\
\text { além das diretrizes }\end{array}$ & $\begin{array}{l}\text { MOURA, Renata } \\
\text { Heller de,; LUZIO, } \\
\text { Cristina Amélia. }\end{array}$ & $\begin{array}{l}\text { Interface } \\
\text { Comunicação, } \\
\text { Saúde e } \\
\text { Educação. }\end{array}$ & $\begin{array}{l}\text { Propor uma reflexão } \\
\text { acerca da funçáo apoio } \\
\text { na implementaçáo do } \\
\text { NASF, com ênfase para } \\
\text { o apoio institucional }\end{array}$ \\
\hline 2014 & $\begin{array}{l}\text { Qualidade de vida } \\
\text { no trabalho de } \\
\text { profissionais do NASF } \\
\text { no município de São } \\
\text { Paulo }\end{array}$ & $\begin{array}{l}\text { LEITE, Denise } \\
\text { Fernandes; } \\
\text { NASCIMENTO, } \\
\text { Débora Dupas } \\
\text { Gonçalves do; } \\
\text { OLIVEIRA, Maria } \\
\text { Amélia de Campos. }\end{array}$ & $\begin{array}{l}\text { Physis Revista } \\
\text { de Saúde } \\
\text { Coletiva }\end{array}$ & $\begin{array}{l}\text { Identificar as } \\
\text { percepçóes acerca da } \\
\text { QVT dos profissionais } \\
\text { do NASF, e os } \\
\text { aspectos facilitadores } \\
\text { e dificultadores no } \\
\text { cotidiano do trabalho }\end{array}$ \\
\hline 2013 & $\begin{array}{l}\text { Perspectivas dos } \\
\text { terapeutas ocupacionais } \\
\text { sobre sua inserção nos } \\
\text { núcleos de apoio à saúde } \\
\text { da família (NASF) de } \\
\text { Fortaleza, CE }\end{array}$ & $\begin{array}{l}\text { REIS, Fernanda; } \\
\text { VIEIRA, Ana Cléa } \\
\text { Veras Camurça }\end{array}$ & $\begin{array}{l}\text { Cadernos } \\
\text { Barsileiros } \\
\text { de Terapia } \\
\text { Ocupacional }\end{array}$ & $\begin{array}{l}\text { Compreender a } \\
\text { inserçáo do terapeuta } \\
\text { ocupacional no NASF }\end{array}$ \\
\hline
\end{tabular}




\begin{tabular}{|c|c|c|c|c|}
\hline $\begin{array}{c}\text { Ano de } \\
\text { Publicação }\end{array}$ & Título & Autores & Revista & Objetivos do estudo \\
\hline 2013 & $\begin{array}{l}\text { Estudo do trabalho e } \\
\text { do trabalhar no Núcleo } \\
\text { de Apoio a Saúde da } \\
\text { Família }\end{array}$ & $\begin{array}{l}\text { LANCMAN, } \\
\text { Selma et al }\end{array}$ & $\begin{array}{l}\text { Revista de } \\
\text { Saúde Pública }\end{array}$ & $\begin{array}{l}\text { Compreender as } \\
\text { características da } \\
\text { organização, das } \\
\text { condiçóes de trabalho e } \\
\text { das vivências subjetivas } \\
\text { relacionadas ao } \\
\text { trabalhar de dois NASF }\end{array}$ \\
\hline 2013 & $\begin{array}{l}\text { Fisioterapeutas } \\
\text { integrantes do Núcleo } \\
\text { de Apoio à Saúde da } \\
\text { Família do Estado } \\
\text { de Santa Catarina: } \\
\text { competências e desafios }\end{array}$ & $\begin{array}{l}\text { BELETTINI, } \\
\text { Nathiele Plácido; } \\
\text { TUON, Lisiane }\end{array}$ & $\begin{array}{l}\text { Fisioterapia } \\
\text { Brasil }\end{array}$ & $\begin{array}{l}\text { Identificar as } \\
\text { competências, os } \\
\text { desafios e as principais } \\
\text { demandas dos } \\
\text { fisioterapeutas do } \\
\text { NASF }\end{array}$ \\
\hline 2013 & $\begin{array}{l}\text { Fisioterapia e Núcleo } \\
\text { de Apoio à Saúde da } \\
\text { Família: conhecimento, } \\
\text { ferramentas e desafios }\end{array}$ & $\begin{array}{l}\text { SOUZA, Márcio } \\
\text { Costa et al. }\end{array}$ & $\begin{array}{l}\text { O Mundo da } \\
\text { Saúde }\end{array}$ & $\begin{array}{l}\text { Entender os desafios da } \\
\text { práxis do fisioterapeuta } \\
\text { no NASF }\end{array}$ \\
\hline 2013 & $\begin{array}{l}\text { Núcleo de apoio à saúde } \\
\text { da família: refletindo } \\
\text { sobre as acepçóes } \\
\text { emergentes da prática }\end{array}$ & $\begin{array}{l}\text { SAMPAIO, Juliana } \\
\text { et al. }\end{array}$ & $\begin{array}{l}\text { Revista } \\
\text { Brasileira de } \\
\text { Ciências da } \\
\text { Saúde }\end{array}$ & $\begin{array}{l}\text { Analisar as práticas } \\
\text { profissionais do NASF, } \\
\text { em consonância com } \\
\text { os modelos de apoio } \\
\text { matricial identificados }\end{array}$ \\
\hline 2013 & $\begin{array}{l}\text { A inserção do } \\
\text { profissional de } \\
\text { educação física na } \\
\text { atenção primária à } \\
\text { saúde e os desafios em } \\
\text { sua formação }\end{array}$ & $\begin{array}{l}\text { FALCI, Denise } \\
\text { Mourão; } \\
\text { BELISÁRIO, } \\
\text { Soraya Almeida. }\end{array}$ & $\begin{array}{l}\text { Interface } \\
\text { Comunicação, } \\
\text { Saúde e } \\
\text { Educação. }\end{array}$ & $\begin{array}{l}\text { Investigar a formaçáo } \\
\text { do profissional de } \\
\text { educaçáo física do } \\
\text { NASF para sua inserção } \\
\text { no campo da APS }\end{array}$ \\
\hline 2012 & $\begin{array}{l}\text { Modelos } \\
\text { tecnoassistenciais e } \\
\text { atuação do psiquiatra } \\
\text { no campo da atenção } \\
\text { primária à saúde no } \\
\text { contexto atual do } \\
\text { Sistema Único de } \\
\text { Saúde, Brasil }\end{array}$ & $\begin{array}{l}\text { VANNUCCHI, } \\
\text { Ana Maria Cortez; } \\
\text { CARNEIRO } \\
\text { JUNIOR, Nivaldo }\end{array}$ & $\begin{array}{l}\text { Physis Revista } \\
\text { de Saúde } \\
\text { Coletiva }\end{array}$ & $\begin{array}{l}\text { Estudar o trabalho do } \\
\text { psiquiatra no campo da } \\
\text { APS, com foco na UBS } \\
\text { e no NASF }\end{array}$ \\
\hline
\end{tabular}




\begin{tabular}{|c|l|l|l|l|}
\hline $\begin{array}{c}\text { Ano de } \\
\text { Publicação }\end{array}$ & \multicolumn{1}{|c|}{ Título } & \multicolumn{1}{|c|}{ Autores } & \multicolumn{1}{c|}{ Revista } & Objetivos do estudo \\
\hline 2011 & $\begin{array}{l}\text { Estratégia de saúde da } \\
\text { família (ESF), Núcleo } \\
\text { de Apoio à Saúde da } \\
\text { Família (NASF) e } \\
\text { terapia ocupacional: } \\
\text { problematizando as } \\
\text { interfaces }\end{array}$ & $\begin{array}{l}\text { LANCMAN, } \\
\text { Selma; BARROS, }\end{array}$ & $\begin{array}{l}\text { Revista de } \\
\text { Terapia } \\
\text { Ocupacional } \\
\text { da Oliveira } \\
\text { Universidade } \\
\text { de São Paulo }\end{array}$ & $\begin{array}{l}\text { Contextualizar a } \\
\text { implantaçáo dos } \\
\text { NASF e refletir sobre a } \\
\text { inserçáo e atuação dos } \\
\text { terapeutas ocupacionais } \\
\text { nessas equipes }\end{array}$ \\
\hline 2010 & $\begin{array}{l}\text { Reflexóes sobre } \\
\text { as competências } \\
\text { profissionais para o } \\
\text { processo de trabalho } \\
\text { nos Núcleos de Apoio à } \\
\text { Saúde da Família }\end{array}$ & $\begin{array}{l}\text { OLIVEIRA, Maria } \\
\text { Amélia de Campos }\end{array}$ & $\begin{array}{l}\text { NASCIMENTO, } \\
\text { Saúde }\end{array}$ & $\begin{array}{l}\text { O Mundo da } \\
\text { Apresentar reflexóes } \\
\text { utilizadas no cotidiano } \\
\text { do trabalho no NASF } \\
\text { e as competências } \\
\text { profissionais requeridas } \\
\text { para tal. }\end{array}$ \\
\hline 2010 & $\begin{array}{l}\text { Análise histórica } \\
\text { da trajetória do } \\
\text { profissional do } \\
\text { fisioterapeuta até sua } \\
\text { inserçáo nos núcleos } \\
\text { de apoio a saúde da } \\
\text { família (NASF) }\end{array}$ & $\begin{array}{l}\text { RIBEIRO } \\
\text { RODRIGUEZ, } \\
\text { Michelline }\end{array}$ & $\begin{array}{l}\text { Comunicação } \\
\text { em Ciências } \\
\text { da Saúde. }\end{array}$ & $\begin{array}{l}\text { Apresentar um } \\
\text { levantamento histórico } \\
\text { da trajetória do } \\
\text { fisioterapeuta até sua } \\
\text { inserção no NASF. }\end{array}$ \\
\hline
\end{tabular}

Fonte: os autores.

Este estudo verificou que a organização do trabalho do NASF é influenciada por aspectos tanto da dimensão micro quanto da macropolítica. Para efeito de organização, tais elementos foram agrupados em categorias de acordo com sua similaridade (figuras 2 e 3 ).

\section{Aspectos macropolíticos que influenciam na organização do trabalho do NASF}

Relacionados aos aspectos macropolíticos, foram elencadas como categorias: infraestrutura; gestão do trabalho do NASF; e formação e competências para o SUS (figura 2). 
Figura 2. Aspectos macropolíticos que influenciam na organização do trabalho do NASF

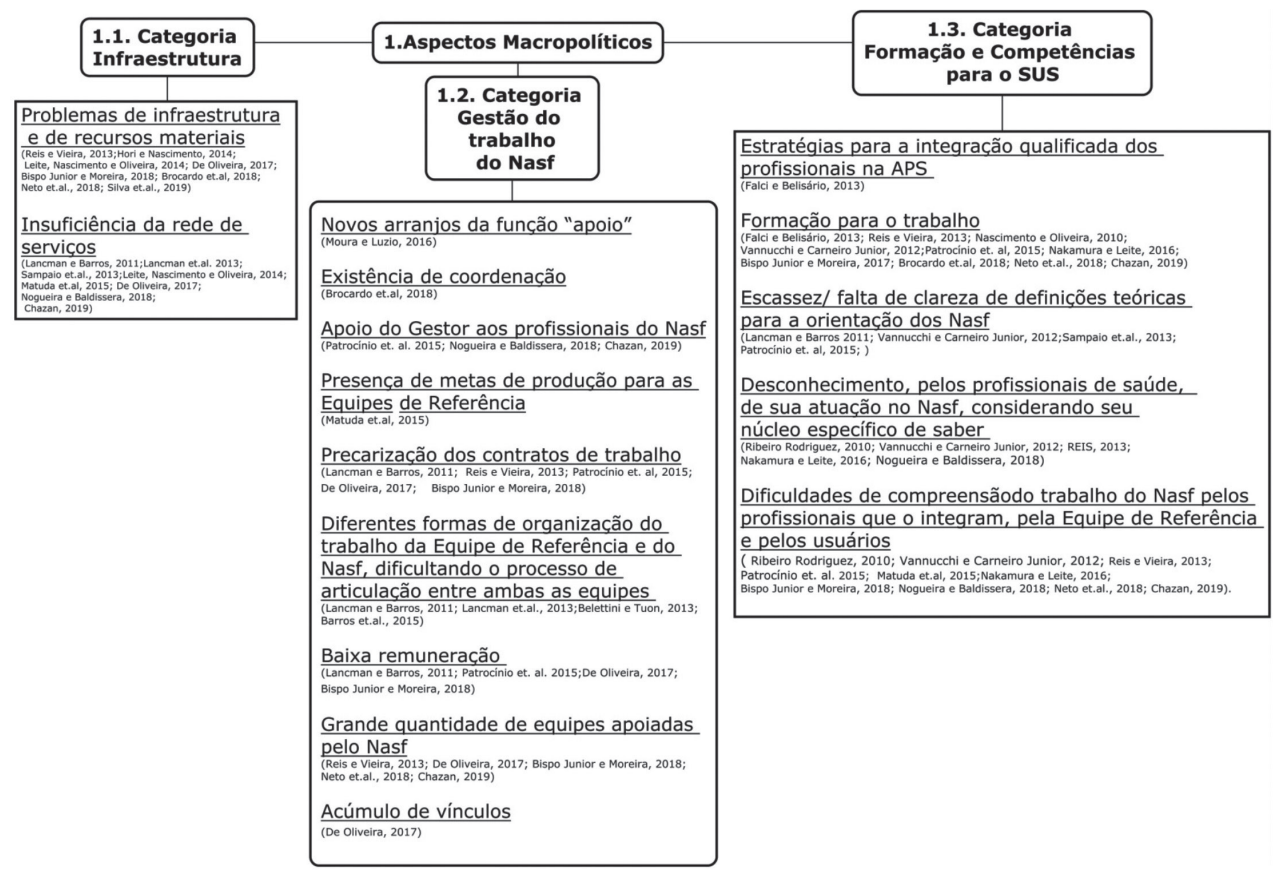

Fonte: os autores, 2020.

\section{Infraestrutura}

Os estudos analisados revelaram que fatores relacionados à infraestrutura e a escassez de recursos materiais para o trabalho foram considerados importantes desafios para a organização e processo de trabalho do NASF.

Cinco artigos identificaram que a ausência de infraestrutura adequada, relacionada à disponibilização de espaço físico para a atuação dos profissionais do NASF, assim como a oferta insuficiente de recursos materiais, interferem negativamente no cotidiano das práticas de trabalho dessas equipes. Na intenção de minimizar tais dificuldades, um estudo relatou que alguns profissionais adotaram estratégias como a utilização de materiais recicláveis, criatividade, improviso, e até mesmo o financiamento da compra de materiais. Da mesma forma, a procura por equipamentos sociais na comunidade para a realização das atividades (como salôes e escolas) e a centralização das ações em um único local foi mencionado em um dos trabalhos como alternativa às fragilidades relacionadas à infraestrutura. 
Cinco estudos pontuaram que há dificuldade na disponibilidade de veículo para deslocamento dos profissionais do NASF, o que acarreta prejuízos para a realização das atividades. Outro artigo verificou que a maior parte das equipes estudadas possuía consultórios compartilhados entre NASF e equipe de referência, salas para reuniôes na UBS, espaços no território para atuação do NASF e disponibilidade de veículo, contribuindo para a organização do trabalho. Conforme dois estudos, a insuficiência da rede de serviços comprometeu a continuidade do cuidado iniciado na $A B$ e, além disso, em seis manuscritos foi evidenciado que uma rede de serviços frágil contribuiu para que os profissionais do NASF atuassem em uma lógica ambulatorial, individualizada e fragmentada, frente à alta demanda por atendimentos, evidenciando, assim, a importância da existência de uma rede estruturada e funcionante.

\section{Gestão do trabalho do NASF}

Um dos estudos identificou que o apoio do gestor favoreceu a implementação do NASF e outro constatou que o comprometimento do gestor local em relação ao apoio matricial e ao NASF foi essencial para o trabalho desse núcleo. Outro artigo evidenciou que o suporte do gestor foi fundamental para processos educativos pautados em diretrizes normativas, como o "Programa de Qualificação da Atenção Primária à Saúde" (APSUS); aponta, no entanto, que a falta de apoio da gestão para realização de reuniôes de equipe entre NASF e Equipe de Referência, bem como para realização de açôes de educação permanente, representou um obstáculo para a realização dessas atividades.

A existência de coordenação para o NASF foi apontada em um manuscrito como fundamental para sua organização e processo de trabalho, sendo que a coordenação comum entre as equipes de referência e o NASF pareceu facilitar a integração entre os trabalhadores. O estabelecimento de metas de produção para as equipes de referência foi mencionado em um estudo como fator que dificultaria a definição de uma agenda compartilhada e a realização de açôes integradas entre essas equipes e o NASF. Além disso, a cobertura pelo NASF de muitas unidades de saúde e o apoio a grande quantidade de equipes de referência foram apontados em três artigos como elementos que tendem a interferir negativamente no resultado do trabalho prestado.

Foram identificados como desafios para o trabalho do NASF: a precarização dos contratos de trabalho dos profissionais (em quatro manuscritos), o acúmulo de 
vínculos empregatícios (em um estudo), assim como a baixa remuneração (em quatro trabalhos). Outra pesquisa identificou que a baixa remuneração dos psicólogos fazia com que a maioria possuísse mais de um vínculo empregatício. Assim, acabavam se dividindo entre a organização de seu trabalho em diferentes estabelecimentos, refletindo no náo cumprimento da carga horária prevista. Em um dos artigos analisados, a maior parte dos profissionais possuía contratos temporários de trabalho, contratados por meio de indicação política, e com remuneraçôes salariais abaixo de suas expectativas, condiçôes essas que diminuíam o desempenho da equipe. Dois artigos evidenciaram a influência da fragilização dos vínculos empregatícios para o trabalho do NASF, com contrataçóes por meio de organização social de saúde (OSS), caracterizando uma forma de terceirização em detrimento do concurso público.

A presença de diferentes formas de organização e dinâmica de trabalho entre equipe de referência e NASF foi pontuada em quatro artigos como desfavorável para o processo de articulação entre ambas as equipes. $\mathrm{O}$ tratamento desigual se refere a exigências de produtividade distintas para ambas as equipes, açóes a serem priorizadas, composição das equipes, demandas e estratégias de trabalho, entre outros elementos. Um estudo revelou a possibilidade da emergência de novos "arranjos" da função apoio - como o apoio institucional, que não integra as diretrizes e portarias ministeriais referentes ao NASF - como uma potência para o processo de trabalho, uma vez que esta face do apoio parece fomentar o trabalho cooperativo em equipe e a troca dos saberes, além de permitir uma aproximação de ações inerentes à gestão e à atenção no desenvolvimento do processo de trabalho.

\section{Formação e competências para o SUS}

Dez estudos sinalizaram que dificuldades de compreensão sobre o trabalho do NASF, pelos profissionais que o integram e pela equipe de referência, trouxeram implicaçóes negativas para o desenvolvimento de um trabalho articulado entre as equipes. Outra condição que dificulta o trabalho integrado se refere à existência de entendimentos conflitantes entre os profissionais do NASF e as equipes de referência em relação à função do matriciamento (um artigo), bem como o desconhecimento de profissionais sobre o significado de conceitos que fazem parte da proposta do NASF, a qual não direcionaria com clareza a forma como trabalho deve ser executado (um estudo). Ademais, identificou-se em outra pesquisa que a escassez de definiçôes teóricas orientadoras da atuação do NASF enquanto equipe 
de apoio, favorece o desenvolvimento do apoio matricial, de diferentes formas nos municípios, de acordo com as demandas locais e convenientes à política de saúde que cada gestor municipal pretende implantar. Dessa forma, a pouca clareza da proposta nos documentos norteadores foi identificada como um dos fatores que dificultam sua efetivação no âmbito local.

Dois estudos denotaram, ainda que a tênue definição das atribuiçóes peculiares às categorias profissionais na esfera do NASF poderia propiciar uma atuação fragmentada de cada profissão. O desconhecimento, pelos profissionais de saúde, de seu papel e de como deve ser desenvolvido o trabalho como apoiador, conforme seu núcleo específico de saber, mostrou ser um elemento limitante para a operacionalização da proposta do NASF, descrito em seis manuscritos. Nesse sentido, um artigo destacou que o fato de uma das normativas ministeriais, contida no exemplar "Cadernos de Atenção Básica - Diretrizes do NASF”, discorrer sobre as açôes a serem realizadas pelas categorias profissionais de fisioterapia, fonoaudiologia e terapia ocupacional em apenas um capítulo, que versa sobre a reabilitação e a saúde integral da pessoa idosa, poderia trazer restriçôes quanto à realização de outras açôes por estes profissionais.

A formação profissional insuficiente para atuação na $\mathrm{AB}$ foi relatada em sete estudos como desafio para o trabalho do NASF, remetendo muitas vezes a uma lógica de cuidado biologicista e que não condiz com as necessidades do SUS. Outro artigo concluiu que estratégias com foco na formação inicial, como a reestruturação curricular, estágios, disciplinas integradas e transversalidade de temas inerentes às políticas públicas, poderiam contribuir para a qualificação de profissionais de educação física para atuarem no NASF. A elaboração de propostas pedagógicas para a formação inicial descoladas da realidade dos serviços públicos de saúde, além do aumento da inserção da educação à distância na pós-graduação, foram pontuados em um estudo como aspectos que poderiam comprometer a aquisição de competências indispensáveis para o trabalho no NASF, como vínculo, acolhimento, escuta e trabalho em equipe. Assim, a Residência Multiprofissional em Saúde da Família, devido à característica de formação em serviço, seria uma estratégia para a formação de profissionais aptos para atuarem no NASF.

Não obstante, duas pesquisas apontaram que a realização de educação continuada e a garantia de espaços de educação permanente auxiliariam na apropriação da proposta do NASF pelos trabalhadores e contribuiriam para a organização do processo de trabalho das equipes de apoio. Ainda sobre a formação, um estudo 
encontrou que somente $45,6 \%$ das equipes analisadas haviam recebido formação específica quando iniciaram a atuação no NASF, e que processos de educação permanente estavam presentes em $51,6 \%$ dessas equipes.

\section{Aspectos micropolíticos que influenciam na organização do trabalho do NASF}

As categorias "Organização do trabalho e relação entre as equipes" e "Características dos profissionais do NASF" foram relacionadas aos aspectos micropolíticos (figura 3).

Figura 3. Aspectos micropolíticos que influenciam na organizaçáo do trabalho do NASF. Londrina-PR, 2020

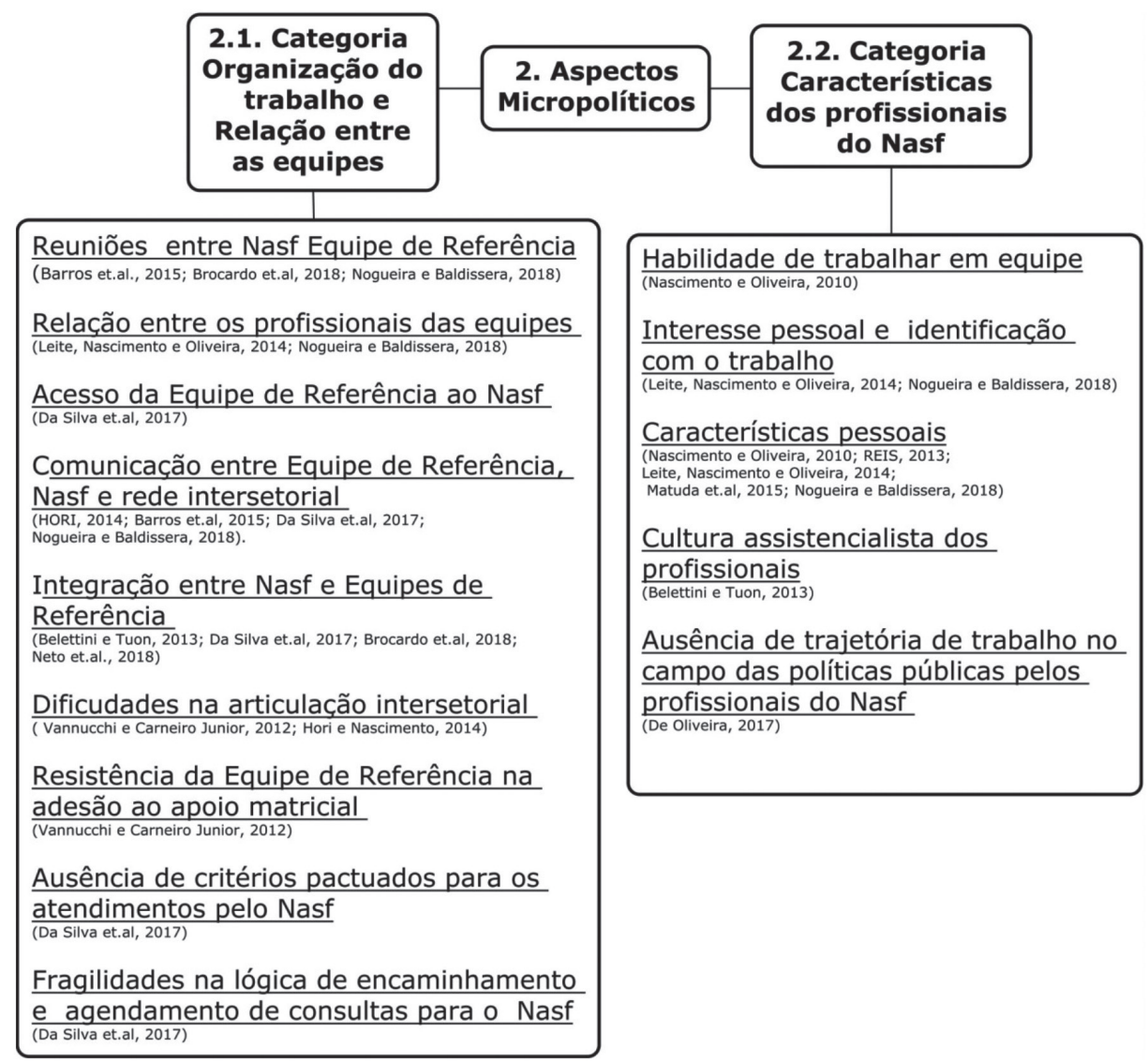

Fonte: os autores, 2020. 


\section{Organização do trabalho e relação entre as equipes}

No contexto da lógica do apoio matricial, égide da atuação do NASF, as reunióes de equipe, tanto entre os profissionais do NASF quanto desses com a equipe de referência, foram consideradas, em dois estudos, primordiais para o trabalho, contribuindo para o planejamento e realização das açôes subsequentes, pactuaçôes e troca de saberes entre os profissionais, ampliando o escopo e a resolutividade das atividades desenvolvidas. Nesse sentido, dois estudos que analisaram o processo de trabalho do NASF a partir de dados provenientes do PMAQ, verificaram que a maioria das equipes realizava planejamento conjunto das atividades e desenvolvia açôes compartilhadas com as equipes de referência. Entretanto, um desses artigos identificou que o compartilhamento de casos não dialogava com a lógica de apoio matricial, uma vez que era realizado através de encaminhamentos por escrito e agendamento de consultas diretamente na agenda do NASF.

Cinco estudos evidenciaram que a presença de uma comunicação efetiva entre os profissionais do NASF, equipes de referência e outros trabalhadores da rede, intra e intersetorial, demonstrou ser um fator importante para o processo de trabalho e o planejamento das açóes conjuntas entre esses atores. Dessa forma, um artigo relatou que dispositivos capazes de garantir o acesso da equipe de referência ao NASF facilitaram a organização do trabalho, sendo o telefone pessoal dos trabalhadores o principal meio pelo qual a equipe de referência acionava esses profissionais diante de situações imprevistas.

Uma pesquisa revelou que a falta de integração entre NASF e equipe de referência constituiu um desafio para o trabalho, ocasionando falha de comunicação, com implicaçóes para o planejamento e pactuação das atividades a serem realizadas no território. O desenvolvimento de processos de educaçáo permanente, essenciais para a lógica de trabalho no contexto da $\mathrm{AB}$ e do NASF, apontado em um estudo, foram favorecidos mediante a existência de um bom relacionamento interpessoal entre ambas as equipes e pela presença de elementos como vínculo, receptividade e parceria.

A frágil articulação com as redes, intra e intersetorial, foi relatada em dois estudos como elemento que influencia na organização do trabalho do NASF, dificultando a elaboração de estratégias de intervenção voltadas para o cuidado integral. Cabe destacar que um desses artigos revelou ausência de articulação intersetorial no enfrentamento a situaçóes de vulnerabilidade socioeconômicas causadoras de 
violência, relacionada tanto à falta de respaldo organizacional quanto à concepção dos profissionais da UBS de que a saúde não seria responsável por essa ação.

\section{Características dos profissionais do NASF}

De modo geral, cinco estudos revelaram que características intrínsecas como disposição, flexibilidade, pró-atividade, resiliência, respeito, vínculo, comprometimento, interesse e atitude acolhedora frente às solicitaçóes da equipe de referência contribuíram para o processo de trabalho do NASF. Também se mostrou favorável, em um desses manuscritos, a presença de habilidades como trabalhar em equipe, acolher, praticar a escuta ativa, comunicar-se e possuir aptidão técnica específica e na abordagem ao usuário. Do mesmo modo, um artigo revelou que características como a maturidade, autonomia profissional, satisfação, identificação com o trabalho e o relacionamento interpessoal, dependendo da forma como se manifestam, podem facilitar ou dificultar o cotidiano do trabalho.

A cultura assistencialista ainda fortemente presente em muitos profissionais foi mencionada em um artigo como fator que dificulta o trabalho do fisioterapeuta no NASF. Outro estudo apontou que a ausência de trajetória profissional no âmbito das políticas públicas, sem o contato com referenciais que remetam à lógica de atuação do NASF, foi limitante para a atuação do psicólogo neste espaço.

\section{Discussão}

Aspectos micro e macropolíticos estão presentes de modo conjunto e indissociável no cotidiano de atuação do NASF. Mediante a análise do material empírico, identificou-se a ocorrência de maior número de desafios em detrimento das potencialidades do NASF. Questóes relacionadas à infraestrutura e insuficiência da rede de serviços foram apontadas como obstáculo para o trabalho do NASF, corroborando resultados evidenciados em outros estudos (CORREIA; GOULART, 2017; GONÇALVES et al., 2015). Em relação à infraestrutura, apesar de o NASF não se constituir enquanto equipe que necessitaria dispor de espaço físico exclusivo para sua atuação, as diretrizes ministeriais preconizam a existência de ambientes e materiais adequados para a realização das açôes, bem como a oferta de transporte oficial, ajuda de custo ou vale-transporte para o deslocamento desses profissionais entre as UBS e visitas domiciliares (BRASIL, 2014). Neste sentido, um estudo 
de revisão integrativa apontou que a configuração favorável do espaço físico e a possibilidade de encontros breves e frequentes entre os profissionais no local de trabalho foram os principais facilitadores para a colaboração interprofissional (MORGAN; PULLON; MCKINLAY, 2015).

Quanto à fragilidade da rede, verificou-se que esta condição contribuiu para a fragmentação do cuidado. Conforme expresso por Melo et al. (2018b), muitas vezes os profissionais do NASF são requeridos para aparelhar a inexistência de uma rede estruturada e a oferta escassa de serviços especializados, voltando-se para uma atuação destoante à lógica de apoio matricial. Nesse sentido, a existência de redes de atenção à saúde para a realização do cuidado especializado é fundamental, de modo a favorecer a integralidade e efetividade da atenção (MELO et al., 2018b). Outros aspectos destacados referem-se à precarização dos contratos de trabalho. Sabe-se que a instabilidade provocada por contratos temporários e terceirizaçôes pode acarretar maior rotatividade entre os trabalhadores, dificultando o trabalho, a qualidade da assistência, a integralidade da atenção e o estabelecimento de vínculo com a população e com os demais profissionais (ALEXANDRE; ROMAGNOLI, 2017).

Ao ser forjado sobre o referencial do apoio matricial, o NASF tem como foco açôes pedagógicas e assistenciais, pautadas em uma relação de colaboração entre os profissionais apoiadores e as equipes de referência. Conforme apontado por Reeves (2016), a prática colaborativa tem grande potencial de promover as habilidades necessárias para trabalhar efetivamente em equipe e contribuir para uma assistência à saúde de melhor qualidade. Entretanto, este estudo desvelou fatores que interferem na integração entre essas equipes, influenciando, assim, o processo de trabalho do NASF. Um desses elementos refere-se à presença de dinâmicas de trabalho e organização distintas entre NASF e equipes de referência. Frente a essas diferenças, torna-se imprescindível lançar mão da pactuação do apoio como potente ferramenta na busca de maior interação entre as equipes. Em uma de suas vertentes, esse dispositivo prevê a ocorrência de negociaçóes rotineiras da forma como deve ocorrer o processo de trabalho do NASF, envolvendo, para isso, os profissionais que o compóem, gestores, equipe de referência e participação social (BRASIL, 2009a).

Outrossim, o processo de trabalho e a integração entre as equipes são prejudicados pela dificuldade de compreensão do trabalho do NASF, reforçado pela escassez e falta de clareza para o direcionamento dessas equipes expressas nos documentos ministeriais. Torna-se fundamental pontuar que a atuação do NASF 
deve ser direcionada às necessidades dos territórios, das equipes e da população (BRASIL, 2014), o que inviabiliza qualquer padronização do processo de atuação desses apoiadores. Assim, apesar da existência de normativas ministeriais para a operacionalização do NASF, na prática tais equipes possuem formas singulares de atuação, a depender do contexto em que estão inseridas. Sobre esse aspecto, um estudo de revisão sistemática revelou que os profissionais contribuem ativamente para a colaboração interprofissional, mass o fazem de diferentes maneiras e, a depender da categoria profissional envolvida, as contribuiçôes também serão diversas (SCHOT; TUMMERS; NOORDEGRAAF, 2020).

Nesse sentido, debate-se a importância de espaços de formação voltados para a qualificação dos profissionais do NASF, como educação permanente, reuniôes de matriciamento ou com outros serviços da rede, cursos e capacitaçóes específicos ofertados pelos gestores (MELO et al., 2018b). É importante enfatizar que a educação permanente permite melhorar processos e transformar as práticas profissionais e da própria organizaçáo do trabalho, uma vez que possibilita articular a gestão, a atenção e a formação, para o enfrentamento dos problemas das equipes (BRASIL, 2009b), sendo indispensável o apoio dos gestores para que seja instituída na realidade dos serviços.

Verifica-se que, apesar de a formação para atuação na $\mathrm{AB}$ constar nas Diretrizes Curriculares Nacionais (DCNs) para os cursos de graduação na área da saúde, essa discussão ainda é pouco fomentada e há insuficiência nesta formação (COSTA et al., 2018). Esses autores analisaram as DCNs para 14 carreiras da saúde e verificaram que a maioria delas apresenta elementos do modelo tradicional de ensino, direcionadas ora para atuaçôes fragmentadas e tecnicistas, ora tecendo orientaçóes voltadas ao cuidado integral, entretanto, com pouca clareza em suas alíneas.

Pecukonis e Bliss (2008) apontam que é rara a preparação para a prática interprofissional e argumentam que isso está relacionado às diversas estruturas culturais e ao centrismo na profissão, que permeiam os ambientes de educação em saúde. Esses autores apontam a necessidade de diminuir o centrismo na profissão por meio da construção de um currículo que promova competência cultural interprofissional. Por outro lado, dada a importância dessa temática na área da saúde, 18 países das Américas apresentaram planos de ação para implementação de educação interprofissional em suas políticas de saúde (SILVA; CASSIANI; FREIRE FILHO, 2018). 
Outra estratégia para fomentar a prática interprofissional é a residência multiprofissional. Além de promover a integração ensino-serviço-comunidade, também possibilita a aquisição de competências, habilidades e atitudes para a qualificação das práticas profissionais no contexto do SUS. Trata-se de um aspecto macropolítico com potencialidade para a ressignificação do perfil e de características dos profissionais que, como constatados por este estudo, são aspectos micropolíticos que influenciam na organização e no processo de trabalho do NASF. Um estudo realizado por Domingos et al. (2015) revelou que, na concepção dos trabalhadores, além de capacitar o profissional residente por meio da formação em serviço, a residência multiprofissional em saúde da família imprimiu alteraçôes na micropolítica do trabalho, propiciando a reflexão do processo de trabalho e a mudança das práticas, incorporando propostas de educação permanente.

Aspectos referentes à organização e relação entre NASF e equipes de referência foram apontados pelos estudos analisados como elementos imprescindíveis para o processo de trabalho dessas equipes apoiadoras, remetendo à necessidade de uma relação de colaboração mútua. Um artigo de revisão que contemplou 12 estudos realizados em seis países diferentes concluiu que a oportunidade de comunicação frequente e informal é essencial para a colaboração interprofissional e que profissionais de saúde que trabalham em estreita proximidade com profissionais de saúde de outras profissóes tiveram interaçôes interprofissionais mais regulares do que aqueles que estavam geograficamente separados (SEATON et al., 2020).

De acordo com a Organização Mundial da Saúde, a prática colaborativa se efetiva no trabalho conjunto entre profissionais de saúde de diferentes núcleos profissionais e usuários, família e comunidade, com vistas a melhorar a qualidade do cuidado em saúde (OMS, 2010). Para Peduzzi e Agreli (2018), a colaboração pressupóe a existência de comunicação efetiva e disposição dos profissionais em contribuir com o trabalho de seus pares, podendo ocorrer tanto nas equipes quanto ser ampliada para a rede de atenção à saúde. Assim, a prática colaborativa tem como eixo fundamental a atençáo centrada no usuário, apoiando-se em suas necessidades de saúde (PEDUZZI; AGRELI, 2018), além das relaçôes entre os profissionais que incluem integração, confiança, respeito, abertura à colaboração, sentimento de pertença, humildade e tempo para ouvir e conversar (SANGALETI et al., 2017). Desta forma, a compreensão dos conceitos relacionados às práticas colaborativas pode ser oportuna para fomentar a colaboração, a interação e a 
execução das açóes integradas e compartilhadas, contribuindo para superar as fragilidades identificadas por este estudo.

\section{Considerações finais}

Esta scoping review constitui um convite à reflexão a respeito dos aspectos micro e macropolíticos que permeiam a organização e o processo de trabalho do NASF, além de suas implicaçôes para a produção do cuidado e resolutividade da atenção à saúde. Em uma perspectiva micropolítica, a forma como se dá a relação entre os trabalhadores e como se organizam no trabalho, bem como suas características e valores pessoais se constituem tanto em potência para as práticas colaborativas e a interprofissionalidade, como em desafio para a efetivação da proposta do NASF. A consolidação de um modelo de atenção pautado na lógica da colaboração, do apoio e da interprofissionalidade, exige a quebra de paradigmas enraizados em nossa cultura, que opera tanto nos espaços de formação na graduação, quanto na realidade dos serviços.

A sistematização dos fatores macropolíticos, como a infraestrutura (espaço físico, rede de serviços) e as condiçôes de trabalho (preparo, vínculo, remuneração) e de como influenciam na organização do trabalho, permitiram concluir que na realidade brasileira estes se constituem em desafios para que os trabalhadores do NASF atuem sob a lógica do apoio matricial e da clínica ampliada e contribuam para a consolidação de um modelo de atenção em defesa da vida. Cabe ainda destacar que, do ponto de vista macropolítico, atravessamentos marcados pela conjuntura atual podem refletir ainda mais incisivamente no trabalho dessas equipes. Ao modificar a nomenclatura para "Núcleos Ampliado de Saúde da Família e Atenção Básica" e estender a responsabilidade para as equipes de $A B$ tradicionais, a nova política de $\mathrm{AB}$ pode potencializar as dificuldades já existentes para que o NASF opere na lógica de apoio matricial. Além disso, ao apoiar uma equipe de referência "disfuncional", impôe-se o risco de os profissionais atuarem como um "ambulatório de especialidades", destoante da perspectiva da clínica ampliada e compartilhada, podendo-se intensificar os desafios encontrados por este estudo.

Receia-se ainda que a nova política de financiamento da $A B$, instituída pelo programa Previne Brasil em novembro de 2019 (BRASIL, 2019a), possa afetar a lógica de apoio matricial preconizada para o NASF, uma vez que os gestores passarão 
a ter autonomia no arranjo das denominadas "equipes multiprofissionais", podendo trazer implicações negativas para o trabalho colaborativo entre NASF e equipe de referência. Dessa forma, torna-se necessário um diálogo ampliado a respeito desse modelo de financiamento, que inclua os diversos atores do SUS (ABRASCO, 2019).

Aponta-se a necessidade da implantação de estratégias no sentido de dirimir os obstáculos desvelados por esta scoping review. Nesse sentido, apesar da potência da micropolítica como propulsora de mudanças para qualificar o trabalho das equipes, considera-se fundamental iniciativas da esfera macropolítica a fim de consubstanciar esse processo. Ressalta-se que os artigos que integraram esta revisão em sua maioria abordaram aspectos referentes aos desafios e fragilidades do processo de trabalho do NASF, encontrando-se, como lacuna de pesquisa, estudos que explorem as potencialidades do trabalho dessas equipes. Reforça-se, portanto, a necessidade de criaçáo de espaços de educação permanente no cotidiano das equipes, o estabelecimento de ferramentas de cogestáo e o incentivo a iniciativas que fomentem a integração ensino-serviço-comunidade, que possam tecer as bases para que o NASF seja capaz de operar à luz do apoio matricial frente às necessidades requeridas pelo território. ${ }^{1}$

\section{Referências}

ASSOCIAÇÃO BRASILEIRA DE SAÚDE COLETIVA. Nota Abrasco sobre as propostas de mudança na PNAB em Saúde. Rio de Janeiro, 29 set. 2019. Disponível em: <https://www. abrasco.org.br/site/outras-noticias/institucional/nota-abrasco-sobre-as-propostas-de-mudancana-politica-nacional-de-atencao-basica-em-saude/43010/>. Acesso em: 20 out 2019.

AleXANDRE, M. L.; ROMAgnOli, R. C. Prática do Psicólogo na Atenção Básica SUS: conexôes com a clínica no território. Contextos Clínicos, v. 10, n. 2, p. 284-299, jul-dez 2017. Disponível em: <http://revistas.unisinos.br/index.php/contextosclinicos/article/view/ ctc.2017.102.12>. Acesso em: 20 mar 2019.

ANJOS, K. F. et al. Perspectivas e desafios do núcleo de apoio à saúde da família quanto às práticas em saúde. Saúde em Debate, v. 37, p. 672-680, 2013. Disponível em:<http://www.scielo. $\mathrm{br} /$ scielo.php?script=sci_arttext\&pid=S0103-11042013000400015\&lng=en\&nrm=iso $>$. Acesso em: 29 abr. 2019.

ARAUJO NETO, J. D. et al. Aspectos restritivos à integralidade nos Núcleos de Apoio à Saúde da Família: o olhar dos stakeholders. Physis: Revista de Saúde Coletiva. Rio de Janeiro, v. 28, p. e280417, 2019. 
BARR, H. et al. Effective interprofessional education: argument, assumption and evidence. Oxford: Blackwell, 2005. 208p.

BISPO JÚNIOR, J. P.; MOREIRA, D. C. Educação permanente e apoio matricial: formação, vivências e práticas dos profissionais dos Núcleos de Apoio à Saúde da Família e das equipes apoiadas. Cadernos de Saúde Pública, v. 33, p. e00108116, 2017. Disponível em <http://www. scielo.br/scielo.php?script=sci_arttext\&pid=S0102-311X2017000905010\&lng=pt\&nrm=iso $>$. Acessos em: $1^{\circ}$ mar. 2019.

BRASIL. Ministério da Saúde. Cadastro Nacional de estabelecimentos de Saúde. Brasília, 2019. Disponível em: <http://tabnet.datasus.gov.br/cgi/tabcgi.exe?cnes/cnv/equipebr.def >. Acesso em: $1^{\circ}$ maio 2019b.

. Ministério da Saúde. Portaria n1 154, de 24 de janeiro de 2008. Cria os Núcleos de Apoio à Saúde da Família - NASF. Disponível em: <http://bvsms.saude.gov.br/bvs/saudelegis/ gm/2008/prt0154_24_01_2008.html>.Acesso em: 29 abr. 2019.

. Ministério da Saúde. Secretaria de Atenção à Saúde. Departamento de Atenção Básica. Diretrizes do NASF. Brasília: Ministério da Saúde, 2009a (Caderno de Atenção Básica, 27).

. Ministério da Saúde. Secretaria de Atenção à Saúde. Departamento de Atenção Básica. Núcleo de Apoio á Saúde da Família - Volume 1: Ferramentas para a gestáo e para o trabalho cotidiano. Brasília: Ministério da Saúde, 2014 (Caderno de Atenção Básica n. 39).

Ministério da Saúde. Secretaria de Atenção Primária. Portaria no 2.436, de 21 de setembro de 2017. Aprova a Política Nacional de Atenção Básica, estabelecendo a revisão de diretrizes para a organização da Atenção Básica, no âmbito do Sistema Único de Saúde (SUS). Brasília, set. 2019. Disponível em: <https://bvsms.saude.gov.br/bvs/saudelegis/gm/2017/ prt2436_22_09_2017.html>. Acesso em: 18 mar. 2019.

Ministério da Saúde. Secretaria de Atenção Primária. Portaria no 2.979, de 12 de novembro de 2019. Institui o Programa Previne Brasil, que estabelece novo modelo de financiamento de custeio da Atenção Primária à Saúde no âmbito do Sistema Único de Saúde. Brasília, nov. 2019. Disponível em : <http://www.in.gov.br/en/web/dou/-/portaria-n-2.979-de12-de-novembro-de-2019-227652180>. Acesso em: 18 mar. 2019a.

- Ministério da Saúde. Secretaria de Gestão do Trabalho e da Educação na Saúde. Departamento de Gestão da Educação na Saúde. Política Nacional de Educação Permanente em Saúde. Brasília, DF, 2009b. Disponível em: <http://http://bvsms.saude.gov.br/bvs/publicacoes/ politica_nacional_educacao_permanente_saude.pdf>. Acesso em: 26 set 2019.

CAMPOS, G. W. S. et al. A aplicação da metodologia Paideia no apoio institucional, no apoio matricial e na clínica ampliada. Interface-Comunicação, Saúde, Educação, v. 18, p. 983-995, 2014. Disponível em: <http://www.scielo.br/scielo.php?pid=s141432832014000500983\&scrip t=sci_abstract\&tlng=pt>. Acesso em: 18 out. 2019. 
CECILIO, L. C. O. Micropolitica e hospital: elementos teóricos. Tese (Livre-docência) Universidade Federal de São Paulo, São Paulo, 2007.

CORREIA, P. C. I.; GOULART, P. M.; FURTADO, J. P. A avaliabilidade dos Núcleos de Apoio à Saúde da Família (NASF). Saúde em Debate, v. 41, p. 345-359, 2017.

COSTA, D. A. S. et al. Diretrizes curriculares nacionais das profissóes da Saúde 20012004: análise à luz das teorias de desenvolvimento curricular. Interface-Comunicação, Saúde, Educação, v. 22, n. 67, p. 1183-95, 2018. Disponível em:< https://www.scielo.br/scielo. php?script=sci_abstract\&pid=S1414-32832018000401183\&lng=en\&nrm=iso\&tlng=pt $>$. Acesso em 27 set 2019.

DOMINGOS, C. M. et al. Potencialidades da Residência Multiprofissional em Saúde da Família: o olhar do trabalhador de saúde. Interface-Comunicação, Saúde, Educação, v. 19, p. 1221-1232, 2015. Disponível em:< http://www.scielo.br/scielo.php?pid=S141432832015000401221\&script=sci_abstract\&tlng=pt>. Acesso em: 27 set 2019.

FERREIRA, J. S.; LADEIA, L. E. G. As Implicaçôes da Política Nacional de Atenção Básica (PNAB) na Dinâmica dos Serviços de Saúde. Rev. Mult. Psic., v. 12, n. 42, p. 681-695, 2018.

GILLES, I. et al. Financial barriers decrease benefits of interprofessional collaboration within integrated care programs: results of a nationwide survey. International journal of integrated care, v. 20 , n. $1,2020$.

GONÇALVES, R. M. A. et al. Estudo do trabalho em Núcleos de Apoio à Saúde da Família (NASF), São Paulo, Brasil. Revista Brasileira de Saúde Ocupacional, v. 40, n. 131, p. 59-74, 2015.

LEVAC, D.; COLQUHOUN, H.; O'BRIEN, K. K. Scoping studies: advancing the methodology. Implementation science, v. 5, n. 1, p. 69, 2010. Disponível em: <http://www.ncbi. nlm.nih.gov/pubmed/20854677>. Acesso em: 9 maio 2019.

MALTA, D. C.; MERHY, E. E. O percurso da linha do cuidado sob a perspectiva das doenças crônicas não transmissíveis. Interface-Comunicação, Saúde, Educação, v. 14, p. 593-606, 2010.

MELO, E. A. et al. Dez anos dos Núcleos de Apoio à Saúde da Família (NASF): problematizando alguns desafios. Saúde em Debate, v. 42, p. 328-340, 2018b.

MELO, E. A. et al. Mudanças na Política Nacional de Atenção Básica: entre retrocessos e desafios. Saúde em Debate, v. 42, número especial 1, P. 38-51, set 2018a.

MIKAEL, S. S. E.; CASSIANI, S. H. B.; SILVA, F. A. M. The PAHO/WHO Regional Network of Interprofessional Health Education. Revista Latino-Americana de Enfermagem, v. $25,2017$.

MORGAN, S.; PULLON, S.; MCKINLAY, E. Observation of interprofessional collaborative practice in primary care teams: an integrative literature review. International journal of nursing studies, v. 52, n. 7, p. 1217-1230, 2015. 
MOROSINI, M. V. G.; FONSECA, A. F.; LIMA, L. D. Política Nacional de Atenção Básica 2017: retrocessos e riscos para o Sistema Único de Saúde. Saúde em Debate, v. 42, p. 11-24, 2018. MULVALE, G.; EMBRETT, M.; RAZAVI, S. D. Gearing Up'to improve interprofessional collaboration in primary care: a systematic review and conceptual framework. BMC family practice, v. 17, n. 1, p. 83, 2016.

OBSERVATÓRIO DE ANÁLISES POLÍTICAS EM SAÚDE. Centro de Documentação Análise Política em Saúde. Atenção Primária à saúde: mudanças acendem alerta. Boletim Projeto de análise política no Brasil (2013-2017), ano 4, n. 24, jul-ago 2019. Disponível em: <https://www.analisepoliticaemsaude.org/oaps/boletim/edicao/24/>. Acesso em: 18 out 2019.

PECUKONIS, E.; DOYLE, O.; BLISS, D. L. Reducing barriers to interprofessional training: promoting interprofessional cultural competence. Journal of interprofessional care, v. 22, n. 4, p. 417-428, 2008.

PEDUZZI, M.; AGRELI, H. F. Trabalho em equipe e prática colaborativa na Atenção Primária à Saúde. Interface-Comunicação, Saúde, Educação, v. 22, p. 1525-1534, 2018.

REEVES, S. Porque precisamos da educação interprofissional para um cuidado efetivo e seguro. Interface-Comunicação, Saúde, Educação, v. 20, p. 185-197, 2016.

SANGALETI, C. et al. Experiences and shared meaning of teamwork and interprofessional collaboration among health care professionals in primary health care settings: a systematic review. JBI database of systematic reviews and implementation reports, v. 15, n. 11, p. 2723-2788, 2017.

SCHOT, E.; TUMMERS, L.; NOORDEGRAAF, M. Working on working together. A systematic review on how healthcare professionals contribute to interprofessional collaboration. Journal of interprofessional care, v. 34, n. 3, p. 332-342, 2020.

SEATON, J. et al. Allied health professionals' perceptions of interprofessional collaboration in primary health care: an integrative review. Journal of Interprofessional Care, p. 1-12, 2020.

WORLD HEALTH ORGANIZATION et al. Framework for action on interprofessional education and collaborative practice. Geneva: WHO, 2010. Disponível em: <https://www.who. int/hrh/resources/framework_action/en/> Acesso em: 26 set 2019.

\section{Nota}

${ }^{1}$ D. A. A. Mazza: revisão bibliográfica, seleção e análise dos artigos; redação do manuscrito. B. G. Carvalho: seleção e análise dos artigos; redação do manuscrito. M. N. de Carvalho: concepção, análise e redação do manuscrito. F. de F. Mendonça: revisão crítica do manuscrito e aprovação da versão final. 


\section{Abstract}

\section{Macro and micropolitical aspects in the organization of work at NASF: what does scientific production reveal?}

This article aims to analyze the influence of macro and micropolitical aspects on the organization and work process of Nasf. This is a scoping review, conducted in June 2020, in the Lilacs and Medline databases. It was found that issues related to infrastructure, Nasf work management, training for SUS, relationship between teams and characteristics of Nasf professionals influence the organization and work process of Nasf, attesting the occurrence of a higher number challenges rather than the potential for this process. It is noteworthy that crossings marked by the current conjuncture can strongly reflect on the work of these teams. There is a need to implement strategies to address the obstacles unveiled by this study, such as the creation of permanent education spaces in the daily lives of teams, the establishment of co-management tools, and the encouragement of initiatives that foster integration teaching-service-community.

Keywords: Primary Health Care; patient care team; public health practice; health policy. 